\title{
A educação ambiental na escola básica: diretrizes para a divulgação dos conhecimentos científicos
}

Financiamento: FAPESP

Resumo: O estudo que originou este artigo teve como objetivo compreender as fontes de informação dos(as) professores(as) da educação básica sobre educação ambiental (EA) para contribuir para a inserção desta na escola básica. Foi um estudo qualitativo na modalidade pesquisa de campo e os dados para análise foram coletados por observações e entrevistas com cerca de trezentos professores e professoras em catorze municípios da região central do estado de São Paulo. Apresentamos aqui as conclusões finais do estudo: a sistematização de diretrizes para publicações mais adequadas para a inserção da EA na educação básica. Apontamos, nesse sentido, a necessidade de problematizar com a comunidade científica essas diretrizes, como também de criar, na formação inicial e permanente dos(as) professores(as), espaços de discussão de formas adequadas de busca de informações sobre educação ambiental.

Palavras-chave: Formação de educadores. Fontes de informação. Divulgação de conhecimentos.

\section{Environmental education in elementary school: guidelines for scientific knowledge dissemination}

Abstract: The study from which this paper is drawn aimed to identify and understand elementary education teachers' sources of information on environmental education (EE) to contribute to inserting EE into elementary school. The study was based on a qualitative approach and was conducted using field research. Data were collected by observations and interviews with about three-hundred teachers in fourteen cities in the central region of the state of São Paulo. Here we present the conclusions of the study: the systematization of publication guidelines which could help the insertion of environmental education into elementary education. In that regard, we indicate the need to question such guidelines along with the scientific community, as well as to create, in initial and continuing teacher training, spaces to debate more appropriate ways of searching for information on environmental education.

Keywords: Teacher training. Information sources. Knowledge dissemination.

\section{La educación ambiental en la escuela básica: directrices para la divulgación de los conocimientos científicos}

Resumen: El estudio que originó este artículo tuvo como objetivo comprender las fuentes de información de los(las) profesores(as) de la educación b ásica sobre 
educación ambiental (EA) para contribuir para la inserción de esta en la escuela básica. Fue un estudio cualitativo en la modalidad investigación de campo y los datos para análisis se colectaron por observaciones y entrevistas con cerca de trescientos profesores y profesoras en catorce municipios de la región central del estado de São Paulo. Presentamos aquí las conclusiones finales del estudio: la sistematización de directrices para publicaciones más adecuadas para la inserción de la EA en la educación básica. Apuntamos, en este sentido, la necesidad de problematizar con la comunidad científica esas directrices, como también de crear, en la formación inicial y permanente de los(las) profesores(as), espacios de discusión de formas adecuadas de búsqueda de informaciones sobre educación ambiental.

Palabras clave: Formación de educadores. Fuentes de información. Divulgación de conocimientos.

\section{Introdução: o contexto da investigação}

Considerando a necessidade de compreender a educação ambiental (EA) como um processo de apropriação crítica de conhecimentos, atitudes, comportamentos, ideias, valores, habilidades e hábitos na construção coletiva e participativa da relação responsável da sociedade com o ambiente e também a sua importância na escola, problematizamos a necessidade de formação de educadores ambientais. Entre as complexas e variadas dimensões do processo de formação desses educadores, relacionadas diretamente aos complexos e diversificados elementos do processo pedagógico na escola, está o acesso dos professores ao conjunto de saberes necessários à sua prática educativa cotidiana.

Alguns estudos sobre a inserção da EA nas escolas brasileiras de ensino fundamental indicam a necessidade de conhecermos mais esse processo, ainda um tanto precário. Veiga, Amorim e Blanco Cossío (2005) informam que o Censo Escolar de 2001, o primeiro que incluiu uma questão sobre educação ambiental, constatou que $61,2 \%$ de todas as escolas brasileiras declararam que trabalhavam com essa temática. Esses autores informam ainda que, mais tarde, no ano de 2004, esse percentual saltou para 94\%. Podemos concluir, pelos resultados desses dois censos, que atualmente a educação ambiental está presente em muitas escolas.

$O$ estudo intitulado "O que fazem as escolas que dizem que fazem Educação Ambiental?’, realizado pelo MEC/INEP (TRAJBER; MENDONÇA, 2006) em escolas de ensino fundamental e médio de todo o país, também identificou dados importantes sobre isso. $\mathrm{Na}$ região Sudeste o relatório da pesquisa mostra que um percentual significativo de escolas que trabalham com educação ambiental iniciou seus trabalhos por iniciativa de um professor on grupo de professores, em virtude de um problema ambiental do bairro ou por iniciativa dos alunos. Ainda nesse contexto, os fatores mais importantes da inserção dessa prática nas escolas foram a presença de 
professores qualificados com formação superior e especializados, professores "idealistas" que atuam como lideranças e, em seguida, a formação continuada de professores.

Ainda segundo o referido estudo, grande parte desses trabalhos na escola é desenvolvida na forma de projetos ou através da inserção dos temas em disciplinas especificas, em geral nas aulas de Ciências ou Geografia (água, lixo e reciclagem e poluição e saneamento básico). Esse panorama nos mostra que nas escolas há uma tendência em confundir educação ambiental com ensino de ciências. Se consideramos que essa prática pode ser reforçada pelo material informativo sobre educação ambiental, nosso estudo para a identificação e análise das fontes de informação utilizadas pelos professores pode contribuir para fundamentar a atuação dos(as) professores(as) que se responsabilizam pela educação ambiental na escola de forma mais complexa.

Os(As) professores(as) são, em geral, estimulados a realizar trabalhos com EA, seja pela definição oficial de diretrizes para sua implantação nas escolas, seja pela atualidade do tema ambiental, fortemente divulgado pelos meios de comunicação, mas sentem falta de conhecimentos adequados, tanto do ponto de vista quantitativo como do qualitativo. O estudo supramencionado (TRAJBER; MENDONÇA, 2006) identificou que uma das grandes dificuldades para a inserção da EA nas escolas é a precariedade de recursos materiais, em que estão inseridos materiais de estudo para o aprofundamento de temas ambientais e educacionais, inclusive para a formação permanente dos(as) professores(as). Sem material adequado e em quantidade para realizar seus trabalhos, eles(as) procuram fontes diversas, nem sempre com adequada qualidade científica, o que vem prejudicando o trabalho desenvolvido. Sabemos que essa prática pode empobrecer o processo de inserção da educação ambiental na escola básica.

As formas de inserção da EA nas escolas são muito variadas, assim como o são os muitos fatores determinantes dessas propostas educativas. Com isso, podemos concluir que são variados os temas de pesquisa relevantes para a identificação dessa inserção: que tipo de profissional está envolvido com a EA nessas escolas, qual sua formação e atuação, quais os temas mais recorrentes, há quanto tempo as escolas desenvolvem essas práticas, como estruturam essa inserção, que propostas pedagógicas a caracterizam, entre outros.

Os membros do Grupo de Pesquisa em Educação Ambiental autores deste estudo partiram do princípio de que os recursos pedagógicos procurados pelos professores para as atividades educativas são elementos importantes para compreender a EA praticada nas escolas. Entre estes, destacamos para análise as fontes de informação dos professores sobre EA. Esse recurso foi compreendido por nós como "síntese de múltiplas determinações", isto é, como elemento revelador de diversas dimensões do quadro da EA nas escolas de educação básica, particularmente das concepções, conteúdos e estratégias, ou melhor, como a educação ambiental está inserida no processo de formação dos sujeitos. 
Nossos conhecimentos sobre a EA na escola, resultado das análises de muitos estudos sobre esse tópico, assim como de nossas observações empíricas no ambiente escolar, nos levaram a identificar a desinformação dos(as) professores(as) da educação básica sobre as formas de divulgação dos conhecimentos produzidos sobre EA nos meios científicos. Segundo nossas análises, por um lado, esse desconhecimento dificulta a apropriação consistente de saberes necessários a esse trabalho educativo; por outro, torna a produção dos conhecimentos científicos em EA muito distante das necessidades desses(as) professores(as). Essa constatação nos revelou um relevante problema de pesquisa: a análise das fontes de informação dos(as) professores(as) para seu trabalho com EA. Formulamos, então, o seguinte problema de pesquisa: "quais as diferentes fontes de informação dos(as) professores(as) da educação básica sobre educação ambiental?".

Com esse problema de pesquisa orientando nossas ações, o estudo intitulado "Fontes de Informação dos Professores da Educação Básica: subsídios para a divulgação de conhecimentos acadêmico-científicos sobre educação ambiental' cumpriu várias etapas. $\mathrm{Na}$ primeira, realizamos um mapeamento para identificar os(as) professores(as) que trabalham com educação ambiental nas escolas dos 14 municípios localizados à margem esquerda da Bacia Hidrográfica Tietê-Jacaré, na região de Bauru, SP. Na segunda etapa realizamos observações nas escolas e entrevistas com os(as) professores(as) para coleta de dados. A terceira etapa foi a organização dos dados em categorias para análise e a última etapa constituiu-se na análise dos dados e na redação do Relatório Final. É importante observar que todas as etapas foram planejadas, realizadas e avaliadas coletivamente pelos membros do Grupo de Pesquisa. Obviamente, como um Grupo de Pesquisa ligado a um programa de pós-graduação, seus membros variaram durante os dois anos que duraram os trabalhos de pesquisa. Os autores deste artigo são aqueles que participaram de várias dessas etapas, inclusive a de redação do Relatório Final e sua transformação em artigos para publicação.

Os resultados das etapas do estudo, analisados coletivamente, revelaram-nos importantes dados sobre a inserção da educação ambiental na escola, organizados em cinco categorias: concepção de educação ambiental; atividades desenvolvidas; dificuldades encontradas; fontes de informação e sugestões para fontes de informação. Uma análise mais aprofundada dessas categorias em conjunto levou-nos a uma conclusão: embora a EA na escola tenha sido objeto de legislação ${ }^{1}$ e de diferentes políticas públicas

${ }^{1}$ A Lei no 9795, de 27 de abril de 1999, que estabelece uma Política Nacional de Educação Ambiental, determina, no Artigo $3^{\circ}$, inciso II, que cabe "às instituições educativas promover a educação ambiental de maneira integrada aos programas educacionais que desenvolvem". 
educacionais nos diferentes níveis e sistemas de ensino (federal, estadual e municipal), ela ainda não está inserida na educação escolar de forma significativa. Lembremos que entrevistamos os(as) professores(as) identificados na primeira etapa do estudo, ou seja, aqueles que afirmaram trabalhar com EA nas escolas. Mesmo assim, nossos dados têm em comum uma constatação: a fragilidade qualitativa da inserção da EA na educação escolar.

Os dados coletados e analisados na perspectiva da EA crítica e transformadora, desde a concepção de educação ambiental até as atividades desenvolvidas, recursos didáticos, dificuldades encontradas, assim como as sugestões para publicações, nos mostram que a qualidade das fontes de informação sobre educação ambiental de que os(as) professores(as) lançam mão, para que possam contribuir para sua formação permanente, necessitam incorporar a produção científica em EA. Essas informações necessitam de ações intencionais para, a partir de um processo de reflexão crítica, se transformarem em conhecimentos e saberes elaborados e passíveis de ser socializados por um processo educativo complexo e dinâmico. Nossos resultados, analisados individualmente e no seu conjunto, nos levaram a concluir que são muitos os problemas para a inserção da educação ambiental nos currículos escolares pelas mãos dos(as) professores(as), havendo enormes obstáculos a vencer. No entanto, embora nosso principal objetivo tenha sido identificar e analisar as fontes de informação dos(as) professores(as) sobre EA, neste artigo apresentamos aquilo que consideramos o desdobramento do estudo: seis diretrizes, a título de sugestão, para que as publicações científicas possam contribuir para a inserção da educação ambiental nas escolas de educação básica.

\section{Diretrizes para a divulgação dos conhecimentos científicos em educação ambiental: interpretando os resultados}

Se consideramos a preocupação das relações das sociedades com o ambiente um tema fundamental para a formação humana - crítica, reflexiva e transformadora -, é importante que superemos o que Grün (1996) identificou como uma "área de silêncio da educação moderna": a falta de tematização do ambiente na escola. Portanto, mais do que organizar o estudo sobre o ambiente de forma eventual na escola, é preciso inseri-lo nos currículos escolares, tratandoo como conteúdo - abordado de forma crítica e reflexiva - de formação humana plena. Se somamos isso à afirmação de que a EA é interdisciplinar, podemos concluir que sua inserção na escola, de forma plena, se dá pela incorporação de seus conteúdos ao trabalho escolar, superando as formas disciplinares que 
fragmentam os conhecimentos que serão apropriados pelos alunos, para se organizar de forma interdisciplinar. Podemos ir até mais adiante: a problemática ambiental, por sua natureza interdisciplinar, poderá contribuir para a organização mais flexível do currículo escolar, contribuindo para o trabalho interdisciplinar de todos os conhecimentos tratados na escola básica. Ou seja, a EA pode contribuir para a organização interdisciplinar dos conteúdos escolares se compreendemos que essa nova organização não significa o desaparecimento de conteúdos específicos, nem sequer o desaparecimento das disciplinas, mas uma forma de organização superior (FOLLARI, 1995), no sentido de superar a compartimentalização dos saberes escolares em disciplinas isoladas e estanques, que não se comunicam entre si.

Em outras palavras, a EA pode contribuir para a superação da compartimentalização disciplinar - resultado da concepção hegemônica de ciência sob o paradigma positivista, empirista e cartesiano - em direção a uma organização mais complexa dos saberes escolares. Por sua vez, essa forma mais dinâmica e complexa dos estudos na escola favorecerá a inserção da EA. Essa nova forma de organização curricular poderá criar condições objetivas para garantir a formação de sujeitos críticos e reflexivos, contribuição importante da escola para a construção de uma sociedade mais equilibrada, dos pontos de vista social e ambiental.

A fragilidade da inserção da educação ambiental na escola que se revelou em nosso estudo apareceu, primeiramente, na dificuldade dos(as) professores(as) entrevistados(as) em compreender os próprios objetivos da pesquisa. Por mais que os(as) pesquisadores(as) se preocupassem em esclarecer que investigávamos as fontes de informação dos(as) professores(as) com relação às suas ações educativas ambientais com os alunos, a maioria deles(as) seguiu sobrepondo esse objetivo com a identificação das atividades desenvolvidas por eles e dos materiais didáticos usados com os alunos. Observamos que essa aparente dificuldade, quando debatida coletivamente pelos membros do Grupo de Pesquisa, revelou uma situação bastante preocupante, constituindo, em nossa análise, um dos mais importantes resultados do estudo: um número bastante significativo dos(as) professores(as) obtém informações para a inserção da EA na prática educativa escolar no próprio material didático oferecido aos alunos.

Então, temos que na prática educativa ambiental os(as) professores(as) lançam mão de conhecimentos que, embora buscados em fontes muito variadas, mostram-se fragmentados e superficiais do ponto de vista do necessário domínio dos saberes escolares para a inserção da temática ambiental. Eles(as) revelaram ter, com relação à EA, uma ação educativa muito mais próxima da ideia de "consciência ingênua", discutida por Paulo Freire (1989), e do "senso comum educacional", discutido por Dermeval Saviani (1991), do que de consciência crítica (FREIRE, 1989) e consciência filosófica (SAVIANI, 1991), 
demanda legítima e necessária de qualquer processo educativo em nossa sociedade.

Embora num primeiro momento os participantes do Grupo de Pesquisa tenham identificado a necessidade de investir na formação - inicial e continuada - dos(as) professores(as) da educação básica, como a principal forma de responder às dificuldades encontradas pelo estudo com relação à EA, o contexto de sua prática pedagógica, isto é, o contexto de sua atuação profissional, emergiu como determinante não somente da prática pedagógica mas dos próprios processos de sua formação. Esse contexto refere-se, principalmente, à desvalorização da formação e da atuação profissional dos(as) professores(as), o que foi agravado na trajetória histórica da escola básica no Brasil.

Freire (1989) nos ensina a necessidade, no processo educativo (e aqui ele não se refere especificamente aos educadores, mas aos educandos - embora para esse autor educadores e educandos encontrem-se em um processo educativo conjunto), de superar a "consciência ingênua" pela "consciência crítica". Esse processo, nessa perspectiva, é o próprio processo educativo:

Num primeiro momento a realidade não se dá aos homens como objeto cognoscível por sua consciência crítica. Noutros termos, na aproximação espontânea que o homem faz do mundo, a posição normal fundamental não é uma posição crítica, mas uma posição ingênua. A este nível espontâneo, o homem ao aproximar-se da realidade faz simplesmente a experiência da realidade na qual está e procura. Essa tomada de consciência não é ainda a conscientização porque esta consiste no desenvolvimento crítico da tomada de consciência. A conscientização implica, pois, que ultrapassemos a esfera espontânea de apreensão da realidade, para chegarmos a uma esfera crítica na qual a realidade se dá como objeto cognoscível e na qual o homem assume uma posição epistemológica. (FREIRE, 1980, p. 26).

Num sentido metodológico diferente, fundamentado no Materialismo Histórico-Dialético, Saviani (1991) nos chama a atenção para a necessidade de os(as) professores(as) superarem o senso comum educacional pela "consciência filosófica". Esse autor apresenta essa possibilidade como: partir do senso comum (a realidade assim como se apresenta num primeiro momento - a realidade empírica) e, através de abstrações do pensamento (reflexões teóricas, estudo crítico do conhecimento produzido), alcançar a consciência filosófica (a realidade compreendida de forma mais aprofundada, a realidade pensada, concreta). Então, alcançar a consciência crítica e a consciência filosófica no que diz respeito à formação de professores(as), mais do que oferecer técnicas e práticas de inserção 
da EA na escola, é oferecer-lhes oportunidades de formação que se debrucem sobre as bases teóricas da organização da sociedade, da educação e da EA. Compreendemos esse movimento de superação do senso comum pedagógico como o movimento da práxis.

Isso significa dizer que, por mais que isso tenha sido já discutido na formação de professores(as), os processos de formação voltados para a formação da consciência filosófica levam os(as) professores(as) a superar esse tratamento mais superficial dos conteúdos escolares, entre eles os temas ambientais, cujos saberes escolares estão num nível de apropriação muito aquém do necessário para cumprir o papel da escola de "socialização do saber sistematizado" (SAVIANI, 2008). Nossos dados confirmam o que já tem sido discutido, pois revelam uma fragilidade conceitual muito mais próxima do senso comum pedagógico - também na EA - do que da apropriação crítica e reflexiva de conhecimentos importantes para a formação dos(as) alunos(as). Esse papel da escola de socialização do saber sistematizado pela cultura, diferentemente da compreensão de outras abordagens educativas, é considerado por nós como a forma histórica de contribuir para a democratização de uma sociedade tão desigual como a nossa, principal objetivo da pedagogia histórico-crítica de Saviani (1995) e muitos outros autores.

Nosso estudo revela, como outros já afirmaram (GUIMARÃES, 2004; LOUREIRO, 2006; SEGURA, 2001; TOZONI-REIS, 2008; por exemplo), a fragilidade qualitativa da inserção da EA na escola básica quando analisamos as fontes de informação de que os(as) professores(as) lançam mão para essa inserção. Isso nos leva a considerar a importância de sua inserção no currículo escolar, mas sabemos que esse é um tema delicado para a EA, em cujas práticas podemos identificar uma tendência em desvalorizar os conteúdos escolares como possibilidade concreta da realização de práticas críticas e reflexivas. Nossas discussões foram no sentido de que essa desvalorização tem dificultado, paradoxalmente, a contribuição da EA para a construção de currículos interdisciplinares na organização dos conteúdos no ensino de crianças e jovens em nossas escolas.

As análises sobre os dados coletados em nossa pesquisa sobre as fontes de informação dos(as) professores(as) em EA nos trouxeram resultados importantes para pensarmos a EA escolar. No entanto, neste artigo apresentamos os resultados para aquele que foi um dos objetivos do estudo, contribuir para a maior aproximação das publicações em EA com os(as) professores(as) da educação básica em forma de diretrizes construídas coletivamente pelos membros do Grupo de Pesquisa que realizou o estudo.

A primeira diretriz diz respeito à inserção interdisciplinar da EA na educação escolar: "as publicações em educação ambiental dirigidas aos(às) professores(as) da educação básica devem estimular - na teoria e na prática - a compreensão da inserção interdisciplinar da educação ambiental no currículo 
escolar", compreendendo-a como uma atividade nuclear do currículo, da forma como discutiu Saviani (2008, p. 16):

Vejamos o problema já a partir da própria noção de currículo. De uns tempos para cá se disseminou a idéia de que currículo é o conjunto das atividades desenvolvidas pela escola. Portanto, currículo se diferencia de programa ou de elenco de disciplinas; segundo essa acepção, currículo é tudo o que a escola faz; assim, não faria sentido falar em atividades extracurriculares. Recentemente, fui levado a corrigir essa definição acrescentando-lhe o adjetivo "nucleares". Com essa retificação, provisoriamente, passaria a ser a seguinte: currículo é o conjunto das atividades nucleares desenvolvidas pela escola. E por que isto? Porque, se tudo o que acontece na escola é currículo, se apaga a diferença entre curricular e extracurricular, então tudo acaba adquirindo o mesmo peso; e abre-se o caminho para toda sorte de tergiversações, inversões e confusões que terminam por descaracterizar o trabalho escolar. Com isso, facilmente, o secundário pode tomar o lugar daquilo que é principal, deslocando-se, em conseqüência, para o âmbito do acessório aquelas atividades que constituem a razão de ser da escola.

A essa concepção de currículo, como as atividades nucleares desenvolvidas pela escola, acrescentamos mais um adjetivo: interdisciplinar. A inserção da EA na escola, para superar as formas fragilizadas e superficiais como ela tem sido realizada, a despeito de todo o esforço oficial e social, pode ser realizada pelo currículo escolar, compreendido como um conjunto de atividades nucleares interdisciplinares.

Com relação às concepções de EA que nos revelaram os dados coletados com os(as) professores(as) entrevistados(as), podemos observar que elas aparecem de formas variadas, mas quase sempre relacionadas às concepções mais ingênuas. Embora a sociedade exija que professores(as), por sua inserção social (a escola é a principal instituição social de formação humana em nossa sociedade), tenham concepções mais elaboradas acerca de todos os saberes escolares, incluindo, no mundo atual, as questões ambientais, encontramos nos resultados de muitos estudos, em especial nos de Reigota (1995, 1999a, 1999b, 1999c), muito mais formas difusas de compreensão da ação educativa ambiental do que concepções mais elaboradas. A identificação dessas abordagens de EA dos(as) professores(as) nas pesquisas em educação ambiental já foi exaustivamente estudada, criando um quadro de tendências que, embora com "classificações" variadas, têm núcleos comuns. Essas concepções, numa análise crítica, podem ser compreendidas como: disciplinatório-moralistas, já que orientam a prática de EA 
para "mudanças de comportamentos" ambientalmente inadequados, o que também é identificado como "adestramento ambiental"; ingênuo-imobilistas, visto que se preocupam fundamentalmente com a "contemplação" da natureza, centrando o processo educativo na sensibilização ambiental; ativista-imediatistas, pois supervalorizam a ação imediata sobre o ambiente, substituindo o processo de ação-reflexão-ação pelo ativismo ambientalista; conteudista-racionalistas, por orientarem o processo educativo para a transmissão de conhecimentos técnicocientíficos sobre o ambiente, considerando que essa transmissão/assimilação tem como consequência uma relação mais adequada dos sujeitos com o ambiente; critico-transformadoras, haja vista que concebem a EA como um processo político de apropriação crítica e reflexiva de conhecimentos, atitudes, valores e comportamentos com o objetivo de construir uma sociedade sustentável nas dimensões ambiental e social (TOZONI-REIS, 2008).

Nesse sentido, embora esse tema já tenha sido exaustivamente tratado nos trabalhos acadêmicos e científicos em educação ambiental, a segunda diretriz para publicações mais adequadas aos(às) professores(as) da educação básica ainda terá de insistir nesse tema: "as publicações em educação ambiental dirigidas aos(às) professores(as) da educação básica que problematizem as diferentes abordagens na compreensão do ambiente e suas relações com a sociedade, o que implica problematizar também a compreensão conceitual da educação ambiental, podem contribuir para a superação das formas difusas e superficiais encontradas entre eles(as)". No entanto, é importante lembrar que essa problematização da educação ambiental deve ter nas bases teóricas da educação seu fundamento.

As atividades desenvolvidas pelos(as) professores(as) entrevistados(as), outra das categorias de análise que emergiram de nosso estudo, mostram que a mera incorporação da EA ao currículo escolar não implica a sua real inserção na escola. As atividades lúdicas, por exemplo, foram apresentadas como formas descompromissadas com a construção e apropriação dos saberes ambientais, especialmente as atividades ao ar livre e visitas, as dinâmicas e jogos recreativos, o teatro, as brincadeiras, músicas e gincanas; as TICs (Tecnologias de Informação e Comunicação), da forma como apresentadas pelos(as) professores(as), constituem muito mais atividades alternativas às atividades escolares do que atividades nucleares interdisciplinares; as oficinas para a construção de cartazes, maquetes e banners com temas ambientais relatadas pelos(as) professores(as) referem-se a atividades manuais $\operatorname{dos}($ as $)$ alunos(as) nas quais não aparece a preocupação dos(as) professores(as) em potencializar suas possibilidades de apropriação do conjunto de conhecimentos, ideias, valores, comportamentos e atitudes necessários à compreensão das relações entre a sociedade e a natureza; as palestras e debates, sempre sob a responsabilidade de especialistas ou pessoas de fora da escola, não têm merecido, segundo nossa compreensão, o cuidado de serem planejados, executados e avaliados com a participação efetiva dos(as) professores(as) e dos(as) alunos(as) para que sejam aproveitados de forma 
integrada aos estudos ambientais compreendidos no currículo escolar; a leitura e a produção de textos da forma como encontramos nos dados coletados com os(as) professores(as) referem-se ao aproveitamento de textos diversos, de revistas e jornais, além daqueles relacionados, segundo eles(as), ao currículo no estado de São Paulo (SÃO PAULO, 2012), que tem tratado os temas ambientais gerais como "objetivos em si mesmos", isto é, a leitura a que se referiram os(as) professores(as) tem objetivos de leitura, e não de apropriação de conhecimentos. Dessa forma, pelo que pudemos apurar, a abordagem dada a essas atividades não consegue avançar para a pedagogia dos "temas geradores" de Paulo Freire (1980, 1989, entre outros), que exigiriam um aprofundamento nos seus estudos; a proposta pedagógica dos projetos da forma como apresentada pelos(as) professores(as) entrevistados(as) esvazia seu potencial de sistematização participativa de atividades de estudo e pesquisa para constituírem-se em atividades isoladas daquelas que tratam dos saberes escolares; o trabalho de pesquisa tem sido realizado, segundo nossa compreensão dos relatos dos(as) professores(as), sem a orientação metodológica necessária para a transformação dessa atividade num processo criativo e sofisticado de apropriação dos saberes ambientais por parte dos(as) alunos(as); as ações e eventos pontuais indicados pelos(as) professores(as) entrevistados(as) para a prática educativa ambiental na escola relacionam-se, principalmente, às datas comemorativas do calendário nacional, constituindo-se em atividades alternativas às nucleares do currículo escolar, forma que expressa a fragilidade da inserção do estudo da temática ambiental na escola.

Isso significa dizer que identificamos, nos dados coletados e analisados, um conjunto de atividades que também aponta uma terceira diretriz para as publicações em EA para que elas possam atingir mais concretamente os(as) professores(as) da educação básica: "as publicações em educação ambiental dirigidas aos(às) professores(as) da educação básica podem propor atividades, diversas e variadas, com a preocupação de mostrar seu potencial para a inserção dos estudos ambientais no currículo escolar em forma de atividades nucleares interdisciplinares". Entendemos que, desse modo, as publicações podem contribuir para que os(as) professores(as) da educação básica superem as formas pontuais e descompromissadas que as atividades de inserção da EA na escola vêm tomando.

Os recursos didáticos - mais especificamente o uso de material didático tiveram pouco destaque neste estudo porque apareceram muito mais relacionados às fontes de informação $\operatorname{dos}(\mathrm{as})$ professores(as) e às atividades desenvolvidas por eles no trabalho com EA. Mesmo assim, destaca-se a forma difusa como esses recursos foram apresentados pelos(as) professores(as), sugerindo seu uso indiscriminado e relacionado a critérios que se afastam dos critérios pedagógicos no que diz respeito à articulação dos recursos materiais aos conteúdos curriculares na educação escolar. Posto isso, podemos identificar aqui 
a quarta diretriz para as publicações em educação ambiental: “as publicações em educação ambiental dirigidas aos(às) professores(as) da educação básica, ao proporem o uso de diferentes e variados materiais didáticos, precisam teorizar sobre seu uso, destacando a importância de articular a seleção, utilização e produção de material didático para a EA aos saberes ambientais necessários à sua inserção no currículo escolar". Isso significa que as publicações para a formação - inicial e permanente - dos(as) professores(as) da educação básica podem buscar subsídios práticos e teóricos nos estudos pedagógicos sobre material didático, já muito desenvolvidos pelas ciências da educação no âmbito da pedagogia e metodologia de ensino.

Outro ponto de nossos questionamentos aos(às) professores(as) de educação básica entrevistados(as) neste estudo foram as dificuldades encontradas por eles(as) no que diz respeito ao trabalho com educação ambiental com os(as) alunos(as). Nossas análises sobre essas dificuldades revelaram um importante elemento para a inserção da EA na educação escolar: a necessidade de aprofundar as concepções dos(as) professores(as) sobre a própria função da escola em nossa sociedade. Muitos(as) professores(as) indicaram que as dificuldades encontradas por eles(as) estão relacionadas a fatores, segundo a sua própria compreensão, externos à escola. Temos afirmado aqui nossa posição a favor de uma abordagem de EA que valorize os saberes ambientais na organização do currículo escolar. Valorização dos saberes ambientais significa a valorização dos conteúdos escolares, mas não conteúdos vazios de significados sociais e históricos presentes na vida dos(as) alunos(as). Defendemos que o papel da escola é a "socialização do saber sistematizado", ou seja, trata-se de uma instituição social que, para contribuir para o processo de democratização das sociedades nas quais está inserida, tem como papel específico garantir o acesso de todos os sujeitos sociais aos saberes escolares. No entanto, esses saberes somente terão sentido como principal função da educação escolarizada se estiverem integrados à prática social dos sujeitos educandos. Integrados, do ponto de vista teórico e prático, significa que a vida social é o ponto de partida e de chegada dos saberes escolares. Ponto de partida e de chegada significa que a educação escolar somente será realizada como práxis educativa se buscar concretizar-se pela articulação entre os conhecimentos e a prática que explicam a realidade social vivida. Nesse sentido, e somente nesse, defendemos que o papel específico da escola é a garantia do saber sistematizado, o que implica um papel ativo dos(as) professores(as) como mediadores desse processo educativo de apropriação de saberes. É preciso questionar a afirmação dos(as) professores(as) de que o papel da escola não é "educar", mas "ensinar".

Esse foi um ponto da análise de nossos dados que indicaram como quinta diretriz: "as publicações em educação ambiental dirigidas aos(às) professores(as) da educação básica devem problematizar a função específica da escola na apropriação dos saberes ambientais articulando-os a um processo educativo tão 
amplo que possam ser compreendidos para muito além de sua dimensão instrucional". Isso significa dizer que o papel da escola é muito mais do que o ensino - que trata os conteúdos de forma neutra e objetiva - de conhecimentos revelados pelas ciências, é problematizar esses conhecimentos na perspectiva de superar os paradigmas tradicionais tanto na produção de conhecimentos com que se preocupa a ciência moderna quanto na organização da sociedade sob o modo de produção capitalista.

Nossos estudos sobre as fontes de informação dos(as) professores(as) da educação básica sobre EA nos trouxeram indicadores para traçar diretrizes que contribuam para que essas publicações tenham sentido na formação desses(as) professores(as). Quando insistentemente questionamos os(as) professores(as) sobre onde - concretamente - eles(as) buscam subsídios teórico-práticos para a inserção da educação ambiental na escola, eles(as) relataram, nas entrevistas, alguns indicadores que nos levam à constatação de que a grande maioria dos(as) professores(as) busca essas informações em revistas, livros didáticos e jornais. Mais especificamente, os(as) professores(as) entrevistados(as) citaram: revistas (representando $23 \%$ do total de citações), internet em geral e materiais paradidáticos $(14 \%)$, livros didáticos (13\%), seguidos de jornais $(10 \%)$, apostilas (6\%), livros em geral $(5 \%)$ e outros $(15 \%)$.

Analisamos esses dados com duas preocupações fundamentais: as funções das fontes de informação na prática educativa ambiental desses (as) professores(as) e o tipo de informação que eles buscam. De forma bastante resumida, observamos que o material que fornece informações para os(as) professores(as) entrevistados não tem função formativa para eles(as), mas para os próprios alunos(as). Nesse sentido, nossa principal preocupação aqui foi identificar os condicionantes históricos dessa prática, refletindo sobre os contextos social, político, econômico e pedagógico do esvaziamento da dimensão intelectual do trabalho dos(as) professores(as). A especificidade do trabalho intelectual exige uma profunda relação entre teoria e prática, exige que a práxis seja o fundamento das atividades; no entanto, vimos nas formas como eles utilizam as fontes de informação como separam teoria e prática.

As revistas e os jornais foram a fonte de informação de maior peso na formação dos(as) professores(as) como educadores(as) ambientais. Destaca-se o fato de que são revistas que se caracterizam como meios de comunicação para o grande público. As discussões e análises sobre essas revistas nos levaram a considerá-las comunicações dirigidas para a formação da cultura de massa que tem a lógica comercial como princípio editorial, não tendo, portanto, os cuidados necessários com a transmissão de conhecimentos e conteúdos mais elaborados do ponto de vista escolar. Para essa análise consideramos os estudos sobre a indústria cultural e a semiformação, principalmente os de Adorno (1999), que identifica nessa semiformação aspectos distorcidos da realidade social, os quais constituíram-se em veículos de disseminação da ideologia dominante, em especial 
por trazerem informações genéricas para serem rápida e instantaneamente consumidas pelos leitores. Nossas argumentações vão no sentido de que esse material impresso pode servir como ponto de partida para ser trabalhado com alunos em sala de aula, dada a motivação que contém, pela atualidade dos temas e pela linguagem mais próxima da vida prática dos alunos. No entanto, as atividades com esse tipo de recurso material exigem a mediação constante dos(as) professores(as) para que possam ser consideradas atividades de ensino no sentido de apropriação crítica do saber elaborado pela cultura.

Destaca-se ainda em nosso estudo o fato de que a revista Nova Escola foi a mais citada entre os(as) professores(as) entrevistados(as). Nossas análises orientaram-se por um importante estudo (BUENO, 2007) que analisou essa revista. Com base nos estudos de Adorno sobre a indústria cultural e a semiformação, o autor destaca que a revista em questão baseia-se em uma formatação que prioriza um vocabulário simplificado e a disseminação de ilustrações fartas que expõem professores(as) e alunos(as) sorridentes. Ao concebê-la como uma "expressão da semicultura" na sociedade globalizada contemporânea, Bueno (2007, p. 304) destaca:

[...] ao conceber seu modelo editorial apresenta-se como uma tradução, para termos próprios à educação, do mesmo modelo seguido pelas demais revistas de entretenimento do Grupo Abril. Sua fórmula consistiria, assim, em descaracterizar a categoria "professor" da especificidade que ela possui, reduzindo-a a mais um entre outros estereótipos da indústria cultural. Assim como para a adolescente vendese Capricho, para a mulher madura vende-se Nova, para o macho vende-se Playboy, para o homem de negócios vendese Exame, da mesma forma, para o professor, vende-se Nova Escola. [...] Enquadrado como mais um entre os estereótipos da sociedade de massas, o professor, ao lado da adolescente, da mulher madura, do macho, do homem de negócios etc., vê-se anulado como um sujeito universal capaz de pensar o todo. Desincumbido de sua especificidade, ao professor resta apenas o consumo distraído de fórmulas que o põem em sintonia com uma totalidade que assim permanece imune à crítica.

É importante considerar, então, que as revistas citadas pelos(as) professores(as) como fontes de informação (23\% das fontes citadas), em sua maioria, por divulgarem informações genéricas e superficiais sobre o tema ambiental, não são adequadas para a formação e atuação desses profissionais. Essa situação fica ainda mais inadequada se consideramos que os(as) professores(as), via de regra, utilizam-se dessas informações e as reproduzem diretamente para os alunos, sem uma reflexão própria, mediada pelos - espera-se 
- conhecimentos específicos sobre a temática ambiental. Sabemos que as revistas de divulgação científica mais especializadas são importantes na veiculação desses conhecimentos, mas o que constatamos em nosso estudo é que as revistas que nossos(as) entrevistados(as) utilizam, em sua maioria, excluindo a Revista Nova Escola, são revistas de assuntos genéricos, dirigidas ao grande público (Veja, Capricho, Caras e Amiguinho, principalmente).

Outra fonte de informação que os educadores ambientais mencionam como importante na sua busca por informações sobre educação ambiental é o livro didático $(16 \%)$. Esse recurso didático é tão importante na organização do ensino no Brasil que o Ministério da Educação tem um Programa Nacional do Livro Didático (BRASIL, 2008), que consiste em diferentes ações para a consolidação de uma política nacional do livro didático. Esse recurso é muito estudado nas pesquisas em educação e ensino: defendido e criticado. A crítica mais encontrada diz respeito ao caráter de simplificação - e até banalização - dos conteúdos e das propostas didático-metodológicas memorizadoras nele contidas. Isso mostra como o uso desse recurso no trabalho educativo com os(as) alunos(as) merece cuidado.

Para as análises relacionadas ao nosso problema de pesquisa, mais do que a compreensão do uso do livro didático pelos(as) alunos(as), interessa-nos destacar o fato de que os(as) professores(as) utilizam o livro didático como um recurso para sua própria formação em EA, o que sugere que a reflexão de sua prática educativa esgota-se na própria prática. Ao expressarem que utilizam o livro didático para a sua formação profissional, os(as) professores(as) parecem não perceber a diferença entre a atividade formativa de sua prática educativa e a própria prática.

Essa situação coloca-nos uma interessante questão para análise: a função dos(as) professores(as) no processo educativo. Sabemos da importância da função mediadora dos(as) professores(as) nesse processo, que envolve a mediação entre o saber elaborado e a apropriação desse saber pelos(as) alunos(as). Em nosso estudo tivemos indicadores de que nessa mediação os recursos didáticos são supervalorizados. $\mathrm{O}(\mathrm{a})$ professor(a) é o mediador entre o saber elaborado e o saber escolar, é intérprete do saber elaborado na construção do saber escolar, e essa função não pode ser reduzida à apresentação "mecânica" de conteúdos escolares, como, de forma geral, fazem os recursos didáticos. Se trouxermos essas reflexões para a inserção da EA na escola, poderemos observar que, pelos indicadores que temos, essa inserção se dá sem a necessária interpretação dos conhecimentos específicos da EA pelos(as) professores(as).

A simplificação do trabalho educativo que a superutilização dos recursos didáticos acarreta foi discutida por nós tendo como base o estudo realizado por Alves (2004). Numa perspectiva histórica, o autor considera a importância que o "manual didático" tem na educação escolarizada ainda hoje, identificando sua origem na Didática Magna de Comenius. A conhecida proposta de "ensinar tudo 
a todos" desenvolveu aquilo que pode ser considerado a origem da tecnologia educacional, que deveria mediar a relação entre o professor e o aluno: o manual didático. Inspirado pela razão instrumental do emergente modo de produção capitalista, o trabalho didático foi simplificado na proposta da Didática Magna:

O professor, que, até então, precisava ter o domínio de uma
erudição muito acima da média, viu-se submetido ao mesmo
processo de especialização profissional que já atingira o
trabalhador das manufaturas. Como decorrência, a
simplificação do trabalho didático gerou o barateamento
dos serviços prestados pelos professores e, com isso, a
queda dos custos de instrução. Começava-se a tornar viável,
portanto, a universalização da educação. Os manuais
didáticos, enquanto instrumentos de simplificação do
trabalho do professor,assumiram papel central nesse
processo. (ALVES, 2004, p. 173).

Alves (2007) analisa, portanto, a forma histórica de organização do trabalho didático que Comenius concebeu ao pensar na escola moderna que responderia às demandas de seu tempo, do início da sociedade capitalista. Percebe-se, na argumentação do autor, que a divisão do trabalho - característica das sociedades sob o modo de produção capitalista - faz-se presente também no campo da instrução pública, descaracterizando uma das especificidades do professor: o domínio dos saberes. Nesse modo de produção e organização da vida social, o domínio de técnicas e habilidades é mais valorizado e implica, na atividade educativa, a desvalorização do domínio do conhecimento - e, ampliando, dos saberes. Desde então, temos a valorização da prática em detrimento da teoria. Nosso estudo traz indicadores dessa desvalorização em muitas das questões respondidas pelos(as) professores(as), em especial a que identificou as sugestões que eles têm para fontes de informação sobre EA.

Para superar a situação que encontramos em nosso estudo, a formação - inicial e permanente - $\operatorname{dos}($ as) professores(as) voltada para a inserção da EA na escola precisa ser problematizada articulando, radicalmente, a teoria e a prática educativa ambiental. Nesse sentido, é importante realizarmos esforços para a superação do reducionismo da relação teoria-prática que supervaloriza a prática em detrimento da teoria ou a considera como prática educativa imediata. É também importante enfrentar o oposto: a supervalorização da teoria em detrimento da prática. Para a superação desses reducionismos, inclusive na ação investigativa de produção e publicação de conhecimentos científicos, tomemos como principal referência o conceito de "práxis". Compreendida em sua forma plena, a práxis permite avançar nessa superação, contribuindo para a investigação, a publicação e a ação educativa ambiental, ao reconduzir a unidade entre o pensamento e a ação na construção, intencional e consciente, da inserção da EA 
na educação escolar. A práxis contribui para aquilo que lhe é específico: a prática, pensada e refletida, sobre a realidade - social e natural - com objetivos transformadores.

Dessas reflexões sobre a necessidade de articulação radical da teoria com a prática, da necessidade de organizar a ação docente em forma de práxis é que emerge de nosso estudo a sexta diretriz para as publicações em EA que façam sentido para os(as) professores(as) no processo de inserção interdisciplinar da EA no currículo escolar: "as publicações em educação ambiental dirigidas aos(às) professores(as) da educação básica que problematizem a articulação radical de conhecimentos, atividades e recursos que estimulem-nos(nas) a se apropriarem de uma compreensão mais profunda sobre as relações entre a sociedade e a natureza contribuirão para essa inserção". Isto é, precisamos nos esforçar para que nossas publicações explicitem a importância de pautar o pensamento e ação dos(as) professores(as) pela relação teoria-prática de forma a lhes mostrar esse caminho para buscarem a autonomia perdida pelos processos de simplificação da prática educativa.

Com essas seis diretrizes concluímos o estudo. Nossa preocupação em divulgá-las à comunidade acadêmica e científica neste periódico diz respeito aos nossos objetivos de contribuir para que os conhecimentos em educação ambiental produzidos por essa comunidade, hoje muito ricos quantitativa e qualitativamente, possam ter o impacto de que precisamos na inserção interdisciplinar da educação ambiental no currículo escolar.

\section{Conclusão: as formas específicas de divulgação dos conhecimentos em educação ambiental}

Da análise das categorias que organizaram os dados coletados pelos membros do Grupo de Pesquisa emergiram as seis diretrizes que podem contribuir para que nossas publicações científicas em EA tenham um impacto mais significativo no processo de inserção da EA nas escolas de educação básica. As diretrizes tratam, principalmente, da necessidade de produzir e divulgar conhecimentos para a inserção interdisciplinar da educação ambiental no currículo escolar - compreendendo como currículo escolar os conteúdos escolares para além da rigidez da organização disciplinar, mas também com o cuidado de não transformar o currículo em atividades espontaneístas e descompromissadas com os conhecimentos produzidos na história da humanidade a ponto de descaracterizar a educação escolar como tal. Tratam da necessidade, ainda que esse tema pareça esgotado no meio científico da EA, de problematizar suas diferentes abordagens conceituais; da necessidade de produzir e divulgar conhecimentos acerca de atividades de ensino em EA que permitam e facilitem uma abordagem conceitual mais aprofundada, assim como uma abordagem curricular interdisciplinar; da necessidade de produzir e divulgar 
conhecimentos sobre o uso adequado dos recursos didáticos, garantindo o papel mediador dos(as) professores(as); da necessidade de problematizar o papel da escola - em especial da pública - no difícil processo de democratização da sociedade brasileira; e, finalmente, da necessidade de problematizar a importância dos conhecimentos nos processos educativos ambientais, superando as ideias que supervalorizam as atividades e os recursos didáticos em detrimento da apropriação crítica e reflexiva dos conhecimentos.

Essas seis diretrizes revelaram que nossas publicações, quando dirigidas aos(às) professores(as) da educação básica para a inserção da EA, precisam se preocupar em contribuir para a superação das formas simplificadas de tratar o ambiente na escola, pela busca de formas educativas intencionais e sistematizadas para problematizar a ação humana no mundo natural e social, na natureza e no mundo dos grupos que realizam ações sociais no ambiente em que vivem, com vistas à transformação das relações predatórias, social e ambientalmente consideradas. Ou seja, a EA que defendemos exige ser tratada como fenômeno educativo necessariamente social, que se realiza no interior das relações sociais e nessas relações se constitui como um fenômeno crítico e transformador.

É esse o sentido da especificidade da educação escolar tratada por Ribeiro (2001): uma forma específica de "práxis". Reportando-se a Sánchez Vázquez (1968), a autora afirma: "[...] quis o autor dizer, lembrar mais uma vez que, em termos de prática propriamente humana (a educação escolar), não se está no âmbito da pura prática e sim no âmbito da unidade entre teoria e prática" (RIBEIRO, 2001, p. 28). Tozoni-Reis (2009, p. 138) retoma essas ideias lembrando-nos de que "a prática propriamente humana (e, é preciso considerar a força e profundidade do ser humano, pleno, onilateral, no pensamento 'marxista'), implica no processo de formação humana, no processo do sujeito humano tornarse humano, então, a finalidade própria da educação", finalidade de, como tão brilhantemente escreveu Saviani (2008, p. 13), "produzir, direta e intencionalmente em cada indivíduo singular, a humanidade que é histórica e coletivamente produzida pelo conjunto dos homens". Então, a finalidade da educação - e da EA - é construir a humanidade compreendida como um conjunto de conhecimentos, ideias, conceitos, valores, atitudes, hábitos e símbolos que tornam plenos os sujeitos sociais. A educação, essa prática social compreendida como práxis, tem finalidade específica: a "satisfação da necessidade que todo ser humano tem de compreender, a um tempo, o que foi feito/produzido, o que está sendo feito/produzido, e o que pode, tem que ser feito/produzido" (RIBEIRO, 2001, p. 29). A partir dessas reflexões, Tozoni-Reis (2009) afirma que a educação é uma prática específica humana e social, é práxis que se concretiza pela ação-reflexão-ação em dimensão transformadora e como práxis educativa, caracteriza-se como um processo de conhecimento e ação no mundo real para compreendê-lo concretamente, compreendê-lo e transformá-lo. Para a autora (2009, p. 139), "a transformação não se refere ao sujeito individual, 
mas à realidade objetiva, então, a transformação significa o engajamento mais pleno possível na luta pela qualidade das relações sociais: pela educação, pelo ambiente, pela saúde, pela moradia, etc., luta pela construção de uma sociedade mais justa e igualitária, social e ecologicamente".

A educação ambiental se constitui tão complexa e dinâmica que exige, ela própria, um processo educativo fundamentado na ação-reflexão-ação para revelar-se plena de significados concretos das realidades social e ambiental, desvendadas naquilo que podem ter de falsos significados. Assim, uma das possibilidades de ação-reflexão-ação para a EA crítica e transformadora na educação escolar é a formação plena dos(as) professores(as) da educação básica. Essa formação, no dia a dia da prática educativa na escola, pode contar com a contribuição das publicações científicas em EA se elas superarem a distância que ainda pudemos observar entre o mundo acadêmico e a educação básica.

\section{Referências}

ADORNO, Theodor W. Textos Escolbidos. São Paulo: Nova Cultural, 1999. (Coleção Os Pensadores).

ALVES, Gilberto Luiz. A produção da escola pública contemporânea. Campinas, SP: Autores Associados; Campo Grande, MS: Ed. UFMS, 2004.

BRASIL. Ministério da Educação. Programa Nacional do Livro Didático - PNLD. 2008. Disponível em: < http://portal.mec.gov.br>. Acesso em: 03 out. 2012.

BUENO, Sinésio Ferraz. Semicultura e educação: uma análise crítica da revista Nova Escola. Revista Brasileira de Educaşão, v. 12, n. 35, p. 300-307, maio/ago. 2007.

FOLLARI, Roberto A. Algumas considerações práticas sobre interdisciplinaridade. In: BIANCHETTI, Lucídio; JANTSCH, Ary (Org.). Interdisciplinaridade: para além da filosofia do sujeito. Petrópolis: Vozes, 1995. p. 127-157.

FREIRE, Paulo. Conscientização. São Paulo: Paz e Terra, 1980.

- Pedagogia do Oprimido. 13. ed. Rio de Janeiro: Paz e Terra, 1989.

GUIMARÃES, Mauro. A formação de educadores ambientais. Campinas: Papirus, 2004.

GRÜN, Mauro. Ética e educação ambiental: a conexão necessária. Campinas: Papirus, 1996.

LOUREIRO, Carlos Frederico Bernardo. Trajetórias e fundamentos da educação ambiental. 2. ed. São Paulo: Cortez, 2006.

REIGOTA, Marcos. A floresta e a escola: por uma educação ambiental pós-moderna. 3. ed. São Paulo: Cortez, 1999a. 
. Ecologia, elites e "intelligentsia" na América Latina: um estudo de suas representações sociais. São Paulo: Anna Blume: 1999b.

. Ecologistas. Santa Cruz do Sul: EDUNISC, 1999c

. Educação ambiental e representação social. São Paulo: Cortez, 1995. (Coleção questões da nossa época)

RIBEIRO, Maria Luisa Santos. Educação Escolar: que prática é essa? Campinas: Autores Associados, 2001. (Coleção Polêmicas do Nosso Tempo).

SÁNCHEZ VÁZQUEZ, Adolfo. Filosofia da Práxis. Rio de Janeiro: Paz e Terra, 1968.

SÃO PAULO. Secretaria do Estado de Educação. Currículo no Estado de São Paulo. Disponível em <www.saopaulofazescola.sp.gov.br>. Acesso em: 03 out. 2012.

SAVIANI, Dermeval. Do senso comum à consciência filosófica. São Paulo: Editoras Associadas, 1991.

Sobre a natureza e a especificidade da educação. In: Pedagogia históricocrítica: primeiras aproximações. 10 ed, Campinas: Autores Associados, 2008.

SEGURA, Denise de Souza Baena. Educaşão Ambiental na Escola Pública: da curiosidade ingênua à consciência crítica. São Paulo: Anna Blume, FAPESP, 2001.

TOZONI-REIS, Marília Freitas de Campos. Pesquisa-ação em educação ambiental. Pesquisa em Educação Ambiental. v. 3, n. 1, p. 155-169, jan./jun. 2008.

- A pesquisa-ação-participativa em educação ambiental como práxis investigativa e educativa. 2009. 163 f. Tese (Livre-Docência em Educação) - Universidade Estadual Paulista, Botucatu, SP, 2009.

TRAJBER, Raquel; MENDONÇA, Patrícia Ramos (Org.). O que fazem as escolas que dizem que farem educação ambiental? Brasília: SECAD; UNESCO, 2006.

VEIGA, Alinne; AMORIM, Érica; BLANCO COSSÍO, Mauricio. Um retrato da presença da educação ambiental no ensino fundamental brasileiro: o percurso de um processo acelerado de expansão. Brasília: INEP, 2005. 25 p. (Série Documental).

Artigo recebido em 15/06/2011

Artigo aprovado em 11/09/2011 